\title{
DE LA RESISTENCIA A FUEGO EN LOS EDIFICIOS
}

\author{
(ABOUT FIRE-PROOFING IN BUILDINGS)
}

José Luis de Miguel Rodríguez, Arquitecto

\section{RESUMEN}

Se presenta una introducción al fenómeno del fuego, y las variables que definen su severidad, tanto desde el punto de vista del edificio, como del espacio en el que se desarrolla y de los materiales constitutivos de los elementos críticos a fuego: los de sectorización y la estructura. Se define solicitación a fuego y resistencia a fuego. Tras una descripción del modelo de análisis y de las opciones aconsejables en los tipos más frecuentes de edificios, se cuestiona tanto el método de adoptar como significativo un valor de solicitación independientemente del material, como el denominado de tiempo equivalente, que expresa la solicitación en términos de tiempo de la curva normalizada de ensayo, aunque se estima mejor enfocado el segundo, apuntándose mejoras que se podrían introducir para eliminar algunos de sus inconvenientes.

\section{SUMMARY}

An introduction to the phenomenon of fire and the variables which determine its severity, with respect to the building, the space in which it takes place and the component materials of the elements critical to fire: sectioning and structure.

Fire-stress and fire-proofing are defined. After a description of the most frequent types of buildings, the study questions both the method of adopting as important a stress value independent of the material and the method denominated equivalent time, which expresses stress in terms of time on the standardized test curve. Nevertheless, the second is considered most sound and the author suggests improvements designed to eliminate some of its shortcomings.
El incendio es el accidente que con más frecuencia resulta dramático para una construcción. Otras situaciones azarosas como el sismo o la caída de una aeronave son más improbables; el incendio surge esporádica pero constantemente en los edificios. Algunas regulaciones públicas de Edificación hay que dedican ca. si todo su contenido al incendio.

Todo incendio necesita un punto de inicio, material y oxígeno. Aunque se ha reducido el número de fuegos y hornos para calefacción y cocinado, todavía resulta inmensa la cantidad de focos de incendio que existe en los edificios: la ciudad posee una trama tupida de gas y de electricidad, y constantemente se encienden cerillas y mecheros. La observación de un estadio concurrido en horas nocturnas nos da una somera idea de a qué densidad se producen en todo momento chispazos de llama.

Una gran cantidad de los materiales existentes en los edificios no pueden ser sino combustibles. El desarrollo de la química del petróleo permite hoy además una oferta amplísima de productos orgánicos agredibles por el fuego. A cambio, la red de agua a presión -0 la posibilidad de motobombas - hace que sea posible controlar incendios que en otros tiempos era impensable conseguir. La voz cortafuego significaba en origen el muro que se dispone en el espacio entre las formas de cubierta para evitar la propagación del incendio, ya que no era posible verter agua sobre el punto más elevado de la construcción.

Oxígeno hay en los edificios porque lo necesitamos. El pavor ancestral al fuego es debido a que se trata al mismo tiempo de nuestro aliado y nuestro competidor: medra de lo que nosotros mismos necesitamos. No es sólo coincidencia que nuestro alimento y lo que nutre al fuego se mida en calorías, son las mismas, aunque modernamente las midamos en Julios.

La invención del ascensor a principios de este siglo, que - mucho más que cualquier otra cosa- ha permitido construir edificios de más de cuatro plantas, ha significado no sólo un nuevo riesgo adicional, sino además la crisis del sentido común y de la experiencia acumulada durante siglos sobreviviendo a los incendios; la sabiduría popular se estrella ainte este nuevo tipo de construcción: los modelos válidos para un edificio de 
cuatro pisos no sirven en absoluto para uno de quince 0 veinte.

Por todo ello ha sido necesario en los últimos años una importante inversión en materiales de extinción, dispositivos de prevención, instalaciones nuevas - como rociadores-, equipamiento público más costoso, regulaciones de edificación más minuciosas, etc. Aún y todo, en el presente momento no se puede decir que exista una disciplina formalmente construida en torno al tema. Son muy escasas - por no decir inexistentes - las horas académicas destinadas a la explicación de este fenómeno, y muy pocos los ténicos que dominan la materia.

El autor de estas líneas tampoco es experto, pero se ha visto comprometido en el estudio del incendio para poder intervenir en reglamentaciones y normalizaciones en la materia. Lo que sigue es sólo una presentación de lo que ha conseguido entender del tema, sin que por ello se atreva a decir que sea la interpretación más correcta. Tendrán que producirse más documentos sobre incendios, no todos coincidentes, para llegar a establecer un conjunto de términos con significación inequívoca y una manera única de hablar y de referirse al tema.

\section{El incendio}

Nos referimos aquí al fuego que se produce de manera no intencionada e incontrolada dentro de un edificio o construcción. No sabemos en qué medida las definiciones, y menos aún las soluciones que se aportan luego, son trasladables a otros ámbitos como bosques, minas o buques.

El fuego no es sino una reacción química que se mantiene a si misma: una reacción en cadena. La energía de activación para una partícula es suministrada por la reacción de la anterior. Basta pues iniciar el proceso en un punto para que continúe por su cuenta. El fuego se inicia porque combustible, oxígeno y foco o aportación de energía alcanzan un punto crítico. A partir de ello la espiral de producción de energía, inflamación de más puntos, nueva producción de más energía, etc., sólo se detiene espontáneamente cuando falta combustible u oxigeno. En el caso límite -anormal en edificación - si la velocidad de dicho proceso es rapidísima podemos hablar de explosión o de flagración.

No precisa la misma energía de activación un material que otro; y la forma ayuda a ello. Un material combustible como la madera o el carbón no se prestan fácilmente a arder con una simple cerilla en forma de grandes trozos o leños, como sabe todo el que haya intentado encender una chimenea: se debe facilitar la espiral encendiendo al principio astillas o briznas. Por el contrario ese mismo material en polvo puede ser ex- plosivo o presentar ignición espontánea, como sucede en las carboneras. Incluso materiales propiamente incombustibles, como el acero o el aluminio, reducidos a polvo pueden oxidarse tan rápidamente que literalmente arden.

El fenómeno del incendio no puede expresarse sólo en términos de la energía liberada. Por dos motivos, íntimamente relacionados entre sí. El primero porque la simple acumulación de energía no produce efectos. No ahoga una inmensa cantidad de agua... extendida sobre el suelo con un dedo de grueso. Un gigantesco montón de arena a unos pocos grados de temperatura significa quizá mucha energía pero no disponible para casi nada. Lo mismo sucede con la electricidad, que produce efectos no necesariamente por su cantidad: cuenta sobre todo su voltaje. La altura de donde cae el martillo puede tanto o más que su peso. Sin temperatura el calor no afecta.

En segundo lugar porque muchos efectos -entre ellos casi todos los indeseables-, dependen críticamente de la temperatura. Pérdidas de resistencia, dilataciones y agrietamientos, emanación de vapores inflamables, fusión, etc., son fenómenos que suceden a una temperatura y no a otra. Claro está que para conseguir temperatura necesitamos calor, pero aplicado en un sólo punto, y como el calor sólo pasa de los cuerpos calientes a los fríos, la fuente debe poseer suficiente temperatura. Una pequeña llama no prende un leño no porque no posea la temperatura necesaria, sino porque su gran masa la baja al instante. Un simple hilo de cobre en espiral alrededor de una llama de mechero lo extingue: le roba calor a tanta velocidad que la reacción no puede automantenerse en la temperatura resultante.

No somos conscientes de la enorme energía que se desarrolla en la combustión: una tonelada de carbón emite al arder ¡varias veces la de una tonelada de trilita al explotar! La diferencia está en que la trilita lo puede hacer casi instantáneamente, y de ahí su carácter destructivo. Pero una tonelada de carbón, aunque tarde mucho más, emite muchísima más energía.

\section{Efectos del incendio}

La energía liberada en el incendio puede producir efectos devastadores. Cuando a algo se le llama incendio es porque se produce mucha más energía que la que simplemente basta para prender el siguiente punto: sobra energía. Una liberación repentina de energía como la que resulta de la combustión instantánea de una bolsa de gas, produce efectos explosivos; una combustión ralentizada permite disipar inocuamente toda la energía en el aire de forma que la combustión simplemente se mantiene - ese es el funcionamiento de las chimeneas modernas-. 
Básicamente la energía liberada en el incendio se invierte en calor, se destina a incrementar la temperatura de lo que se encuentra al lado del foco. Cuanta más energía se libera en un instante y espacio dados, es más probable que se alcancen temperaturas elevadas, que son las que permiten fenómenos indeseables y la propagación del incendio. A temperatura elevada, una lengua de fuego puede trasladar el incendio de una planta a otra por fachada. Una pared que sufra el incendio por una cara, si se calienta lo suficiente como para alcanzar, del orden de $200^{\circ} \mathrm{C}$ en todo su espesor, provoca automáticamente la aparición del incendio en el otro lado.

De entre los efectos del incendio en los edificios, los peores están asociados a los que se producen sobre los ocupantes. Una temperatura ambiente de $50^{\circ} \mathrm{C}$ es insoportable y de $70^{\circ} \mathrm{C}$ es letal. Los humos, gases y productos resultantes de la combustión son nocivos, irritantes, asfixiantes y, en ocasiones, hasta venenosos, $y$ todos ellos propagados lejos del foco físico del incendio.

En la combustión de productos orgánicos, maderas, tejidos y plásticos, se producen moléculas simples; son inevitables el vapor de agua y el anhídrido carbónico. El aumento de sólo unos puntos en el contenido de anhídrido carbónico del aire, aunque siga existiendo oxigeno y nitrógeno en abundancia, lo vuelve irrespirable. En los edificios el fuego inunda de humo los locales, produciéndose monóxido de carbono en la subsiguiente combustión incompleta, que en pequeñísimas cantidades es venenoso y mortal, y para colmo incoloro e indetectable.

En muchos materiales orgánicos abundan el azufre, nitrógeno, y en otros el cloro, pudiéndose producir además en el incendio vapores sulfurosos, clorhídricos y cianhídricos, altamente agresivos.

El incendio medra sin embargo a sus anchas en esta barahunda de gases, con tal de que exista además suficiente oxígeno. En esta batalla entre las especies humana y la del incendio, existe un nicho seguro para el hombre: éste sobrevive con menos proporción de oxígeno que la que se necesita para mantener un incendio, a cambio de que no exista demasiado anhídrido carbónico. Al menos como solución teórica, la inyección de nitrógeno según se eleva la tasa de anhídrido carbónico da lugar a una atmósfera razonablemente respirable pero incapaz de alimentar un incendio.

Por lo que respecta a los efectos sobre el propio edificio, la elevación de temperatura produce en los materiales constructivos transformaciones y cambio en sus cualidades, aunque no lleguen a arder. El calor fractura y rompe la obra al dilatarse diferentemente sus componentes, varía sus resistencias, módulos de elastici- dad, sus cargas críticas y capacidades portantes, pudiendo producir el colapso de las partes más afectadas, y en cadena, de todo el edificio.

\section{Seguridad a incendio}

La seguridad en caso de incendio implica la prevención de los efectos indeseables del mismo, sobre todo los que afectan a las personas. Nótese que no decimos prevención del incendio, aunque ese tema es extremadamente importante. El almacenamiento de materiales combustibles, el trazado y características de la red de gas y electricidad, las precauciones en los puntos de ignición -como cocinas y calentadores-, el régimen de tenencia del edificio, la regulación de si se puede o no fumar, etc., influyen la probabilidad de un conato de incendio. La disposición de sensores, detectores, y la activación automática de medios de extinción pueden abortar muchos incendios en su inicio, que es cuando resulta más fácil. Pero aun improbable, el incendio puede seguirse dando; no podemos reducir su probabilidad a cero.

Para evitar los efectos indeseables sobre las personas, el edificio debiera estar planteado para que en caso de emergencia -y no sólo por incendio- los ocupantes puedan ponerse a seguro. El edificio debe estar concebido, ocupado, y señalizado de forma que los ocupantes sepan qué hacer y puedan hacerlo. En la mayoría de las ocasiones ponerse a seguro es abandonar el edificio; $y$ en un tiempo razonable es poderlo hacer en no más de dos o tres minutos. Naturalmente si el edificio posee treinta o cuarenta plantas o es muy extenso - piénsese en un aeropuerto-, habrá que contar con alternativas, creando dentro del mismo edificio receptáculos más seguros. En otros casos el carácter de indefensión o de incapacidad motriz de los ocupantes obligará a descomponer cada planta en dos partes independientes - por ejemplo en hospitales-.

Si la emergencia es por incendio, hay que prever además dos cosas. Por un lado la pérdida de visibilidad y de orientación que crean los humos del incendio obligarán a dotar a los puntos críticos o de acumulación en el proceso de evacuación, de balizamiento e iluminación de funcionamiento garantizado -ya que la red eléctrica puede quedar afectada-. Por otro, y sobre todo en los edificios de gran envergadura, en los que ciertas zonas como las escaleras tienen que suponer un lugar seguro, debe dificultarse la invasión de humos mediante artificios como dobles puertas, chimeneas de extracción, presurización, etcétera.

En todo caso, como una insignificante elevación de temperaturas es sumamente agresiva para las personas, las zonas cruciales en el proceso de ponerse a seguro deben tener características adicionales que las hagan menos vulnerables, como son las de poseer ma- 
teriales no colaboracionistas con el incendio, estar convenientemente aisladas y ventiladas, etcétera.

Todo ello para que en los primeros instantes tras la noticia de que se ha declarado un incendio pueda producirse la evacuación, sin esperar al desarrollo mismo del incendio. Adicionalmente habrá que evitar que el propio incendio dañe la construcción por encima de lo razonable, sobre todo si su colapso puede producir victimas o afectar a terceros.

\section{Fases del incendio}

El incendio - no provocado- se inicia en un punto. En los primeros minutos - como sucede con el encendido de una chimenea de leña-, apenas gana en ex-
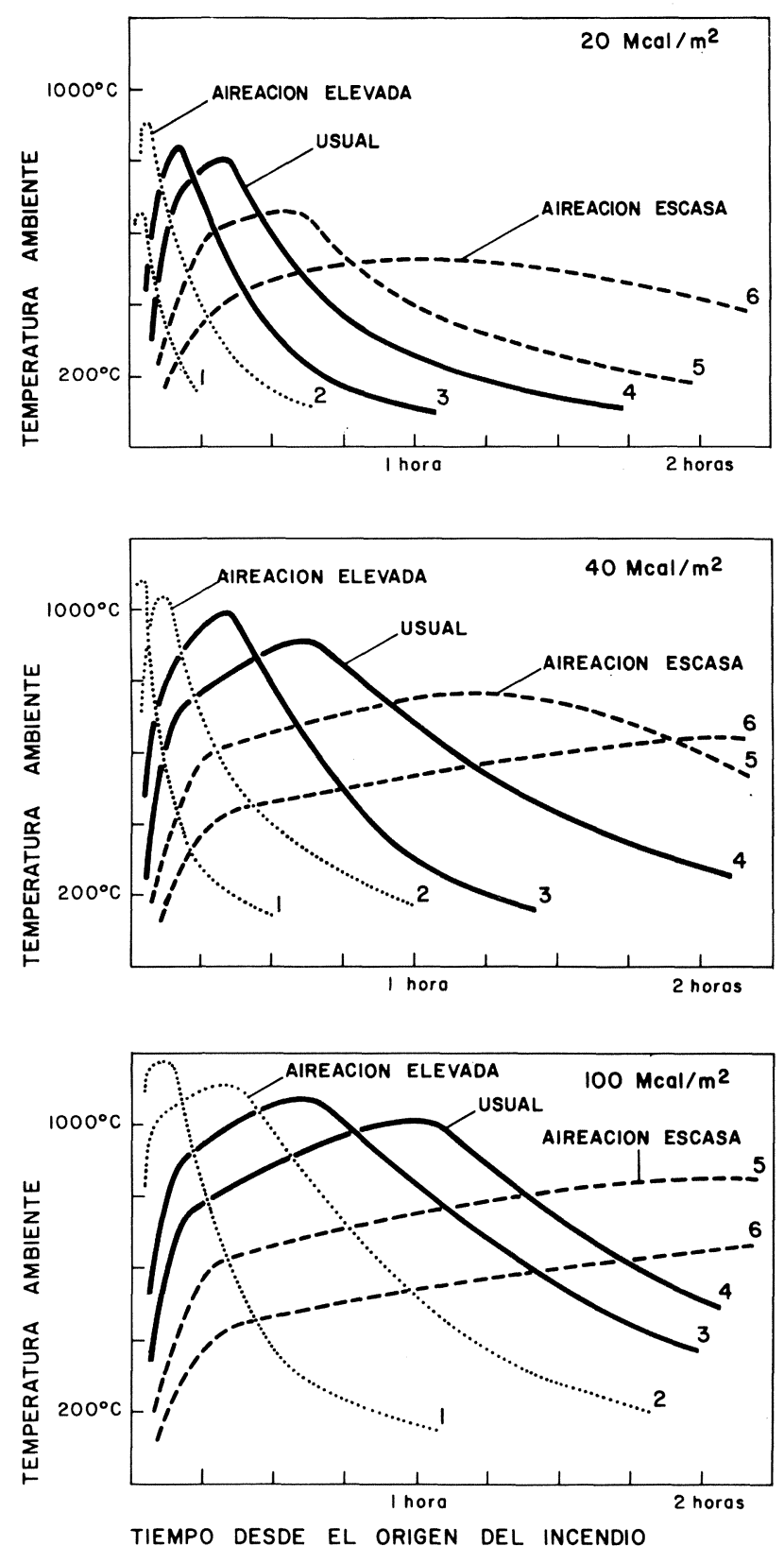

(C) Consejo Superior de Investigaciones Científicas tensión ni en temperatura, no hay demasiados humos, y en esa fase es más un conato de incendio que un incendio propiamente dicho. El fuego puede apagarse en esta fase con suma facilidad, con medios ordinarios, sin ser un profesional.

Pasados algunos minutos sin que se actúe sobre el fo$\mathrm{co}$, el fuego avanza primero por contacto físico, luego inflama a distancia por elevación de la temperatura ambiente y por último traspasa barreras por radiación, como antes indicábamos. El crecimiento es espectacular y rápidamente progresivo. En breves minutos el incendio está plenamente declarado, alcanzando varios centenares de grados, y en ocasiones hasta el millar, y haciendo imposible la supervivencia en el espacio incendiado. A partir de ese instante el incendio sólo puede apagarse con medios potentes, por profesionales, y a distancia. El volumen de humos y gases es importante y éstos se propagan por fisuras, bajo puertas, y por huecos accesibles, a otras partes del edificio. La difusión de humos es impresionante. La falta de visibilidad puede ser prácticamente total en zonas muy alejadas del fuego.

Con oxígeno suficiente todo el material combustible de la zona afectada alcanza la ignición casi simultáneamente. Si el aporte de oxígeno está restringido el incendio continúa en una segunda fase creciendo a expensas del material combustible, pasando a inflamar las zonas limítrofes, mientras que en el foco original empieza a acabarse el material combustible. La tem-

Fig. 1.

$\angle A E V O L U C I O N$ de la temperatura ambiente en el incendio en un edificio depende de numerosos factores. Aquí se representan algunos de ellos. La viñeta superior corresponde a una carga de fuego unitaria de $20 \mathrm{Mcal} / \mathrm{m}^{2}$ y la intermedia a $40 \mathrm{Mcal} / \mathrm{m}^{2}$. La práctica totalidad de las construcciones de pisos se encuentran entre estas dos cate. gorías. A la primera pertenecen edificios como las escuelas, a la segunda viviendas, hoteles y hospitales. La carga de fuego en algunas oficinas y muchos comercios debe determinarse en cada caso; para comparación la viñeta inferior corresponde a $100 \mathrm{Mcal} / \mathrm{m}^{2}$. Las diferentes curvas corresponden a distintas tasas de aireación, en función del tamaño de los huecos al exterior. Las curvas de trazo continuo (3) y (4) se obtienen con ventanas habituales en edificios de pisos. La curva (6) supone que sólo existen troneras, como en un bunker, la (1) se produce en recintos tipo hangar, con un hueco de superficie semejante a la de la planta. Las ordenadas en los primeros minutos no son significativas ya que dependen sobremanera de detalles locales. Las inferiores a $100^{\circ} \mathrm{C}$ no suponen efectos relevantes. Se distinguen en cada curva tres tramos, el primero de elevada pendiente y corta duración, de desarrollo del incendio, la segunda hasta alcanzar el pleno desarrollo y la temperatura máxima con pendiente algo inferior, y la tercera descendente e incurvada. Nótese que los primeros tramos son independientes de la carga de fuego. Al aumentar el aporte de oxígeno el incendio aumenta su temperatura máxima y disminuye su duración, pero, en conjunto desprende menos energía sobre la construcción, se disipa más en los gases de combustión. Con los valores más elevados -curvas (1) y (2) - las fases primera y segunda se confunden. Para mantener la escala no ha sido posible dibujar en todos los casos el desarrollo completo hasta la extinción total. Las figuras se han extraído de los trabajos de Pettersson (1976) que calculó el proceso de incendio a partir de madera como combustible. 
peratura crece más lentamente. Cuando toda la masa combustible está ardiendo se alcanza el pleno desarrollo y la temperatura máxima del incendio. Con oxígeno suficiente el pleno desarrollo se alcanza en minutos, aunque lo habitual es que se tarde de media hora a una hora en alcanzarlo.

Cuando el incendio deja de propagarse comienza a extinguirse por sí sólo. El ataque al fuego no puede hacerse desde las zonas en rescoldo, ya que éstas poseen todavía temperatura insoportable para las personas, aunque los elementos constructivos comienzan a enfriarse. Puede que se enfríen más lentamente que el propio incendio. Esta fase de extinción puede durar desde una hora -en los casos de gran aporte de oxígeno-, hasta más de cuatro - si la combustión es extremadamente lenta-. No es la fase menos peligrosa; las contracciones de la obra pueden producir nuevos problemas, desajustes y colapsos.

El pleno desarrollo del incendio puede afectar simultáneamente a una sola planta si el camino de conexión con las demás es tortuoso para el fuego, o sólo a una parte de la planta si ésta posee profusión de tabiquería - naturalmente de tabiques no combustibles, como es habitual en estos casos-. Si la configuración del edificio lo permite, el pleno desarrollo puede que consiga incluir varias plantas o que se reinicie en otras zonas o plantas por la acción de lenguas de fuego, o por ascuas transportadas por el aire.

Lo descrito es el proceso de un incendio sin intervención. Pero además un incendio puede propagarse, iniciando otro incendio, con su propio desarrollo superpuesto con el anterior. Evidentemente la acción positiva de extinción por voluntarios o por cuerpos especializados de bomberos puede reducir los incendios en duración, temperatura y efectos. Pero la hipótesis de incendio, del lado de la seguridad, no suele tener en cuenta esa circunstancia, en general ventajosa, aunque si en la extinción se usa agua, las operaciones de empapar, calentar, mojar y enfriar, pueden afectar seriamente a las propiedades de los materiales.

\section{Severidad del incendio}

Los incendios pueden poseer distinta envergadura según afecten a más o menos porción del edificio; en general mayor envergadura se traduce en mayor severidad. Por severidad queremos expresar que se producen efectos más graves. Los efectos sobre un determinado elemento constructivo dependen del programa térmico que provoca el incendio, de la temperatura que le haga alcanzar en cada instante.

Sin embargo en cada caso es una variable distinta la que explica la gravedad de los efectos. Por ejemplo para un soporte de madera un incendio se caracteriza más bien por su duración, casi independientemente de las temperaturas que se alcancen, bien entendido que, al ser un incendio, las temperaturas superan el punto de ignición de la madera en todo su desarrollo. Ante el incendio, como la madera es muy mala conductora del calor y la parte carbonizada es además aislante y relativamente impermeable al oxígeno, la acción del incendio reduce la sección transversal a una velocidad prácticamente constante, penetrando una profundidad de unos pocos centímetros por hora.

En acero se produce la situación opuesta: para una pieza de acero es indiferente que el incendio dure más o menos; lo que cuenta es qué temperatura se alcanza. Si el incendio no consigue que la superficie de la pieza llegue a $600{ }^{\circ} \mathrm{C}$ el perfil puede aguantar todo el tiempo que se desee; y decimos en la superficie porque al ser el acero muy buen conductor del calor, la temperatura en un punto de su superficie es casi instantáneamente la de toda su masa. Por el contrario, si el incendio consigue producir en la pieza temperaturas de $700{ }^{\circ} \mathrm{C}$ aunque sea breves minutos, posiblemente colapse.

Ninguno de los dos planteamientos vale para soportes de hormigón. El hormigón es mal conductor y no combustible, pero en líneas generales degenera a una temperatura del orden de $500^{\circ} \mathrm{C}$. El incendio citado en el párrafo anterior que era inofensivo para acero puede colapsar el hormigón: con suficiente tiempo toda la masa del soporte alcanza su temperatura crítica. Paradójicamente el incendio que alcance elevadas temperaturas durante un corto intervalo de tiempo, que es fatal para un soporte de acero, es inocuo para hormigón: no tiene tiempo de alcanzar la temperatura crítica en su interior. Cuando por incendio se alcanzan 1000 grados centígrados en el exterior de la pieza rara vez se ha superado la temperatura crítica en profundidad superior a $3 \mathrm{~cm}$. Para el hormigón y otros tipos de fábricas casi se podría decir que lo característico del incendio es el producto de la temperatura por el tiempo en que ésta se da.

Los razonamientos anteriores son correctos, aunque los incendios descritos sean poco verosímiles. No es fácil que un incendio se desarrolle en un tiempo muy dilatado a una temperatura media, ni que se alcancen altísimas temperaturas sólo breves instantes sin que se acompañe un largo intervalo de temperaturas parecidas. Si es por tiempo, todos los incendios tienen una duración importante; si es por temperatura, en todos los incendios se alcanzan temperaturas elevadas, y si es importante que existan ambas cosas también el incendio provee de ambas. Pero la conclusión es válida: el incendio no puede caracterizarse sino por su diagrama tiempo-temperatura. La severidad depende - según el elemento afectado - unas veces más bien de la tem. 
peratura, otras más bien del tiempo, y otras de ambas cosas. No se puede denominar un incendio más severo que otro independientemente del elemento afectado del que se hable.

Como para cada propósito es pertinente una variable distinta, de ahí la dificultad para hablar de magnitud o intensidad de un incendio: un sólo valor no es capaz de expresarlo. Asi se entiende la dificultad de comunicación entre los expertos. Cada uno ve el incendio de una manera diferente; aunque utilicen las mismas palabras se refieren a cosas muy diferentes. El técnico de madera se refiere insistentemente a la duración y al tiempo del incendio, el de acero habla constantemente de temperaturas y temperatura máxima, y el del hormigón - no sin algo de razón - suele ignorar el tema.

\section{Desarrollo del incendio}

La evolución de la temperatura ambiente en un incendio depende de múltiples factores, para empezar, de la cantidad de material combustible y su modo de arder. A igualdad del resto de factores, cuanto mayor sea dicha cantidad - que, medida en las calorias que desprende al arder, se denomina carga de fuego - , mayor será la severidad del incendio. La carga de fuego debe incluir todo material susceptible de arder, sea de la estructura, de la construcción, de los revestimientos o enseres. En edificios convencionales la carga de fuego debida al uso en promedio por $\mathrm{m}^{2}$ de superficie construida es prácticamente fija.

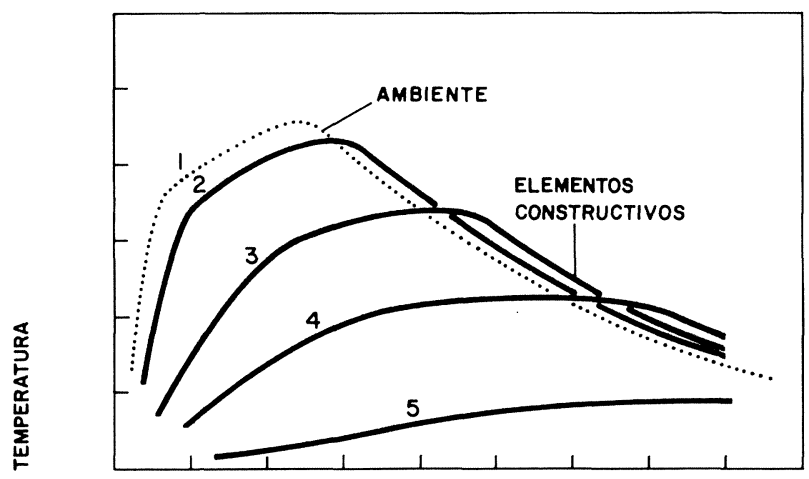

TIEMPO DESDE EL ORIGEN DEL INCENDIO

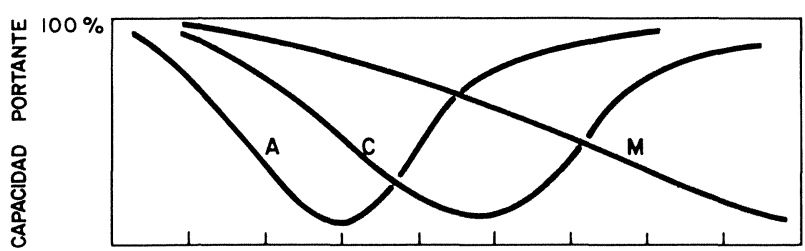

LA EVOLUCION de la temperatura en los elementos constructivos se refleja en esta figura superponiéndola a la de ambiente del incendio para uno de los casos típicos de carga de fuego y aireación intermedias. Todas parecen haber sido obtenidas por arrastre de la (1) que
Como la rapidez con que puede arder un material depende de su forma, para los cálculos se usa la carga de fuego corregida por un factor - que podriamos denominar $m$ - que tenga en cuenta ese aspecto. A efectos del estudio del desarrollo del incendio la carga de fuego de un material equivaldría a $m$ veces la carga real aportada.

El incendio libera una cantidad de energía dada para cada valor de la carga de fuego, pero a un ritmo que varía con las características geométricas del espacio en cuestión, y en particular de las condiciones de aporte de oxígeno y ventilación del local. Una entrada restringida de oxígeno produce una combustión ralentizada, ocasionando un incendio extenso en tiempo pero moderado en temperaturas; por el contrario un aporte de oxígeno generoso reduce el tiempo de incendio pero éste es más vivo y alcanza temperaturas más altas. El factor que caracteriza este comportamiento depende de la presencia de huecos al exterior - presumiblemente rotos desde los primeros minutos de incendio, operando como huecos abiertos-, su situación y tamaño relativos, y, sobre todo, si existen en el techo del recinto analizado.

La energía liberada irradia en todas direcciones pero supone distinta densidad según la superficie sobre la que irradie, de manera que la magnitud de los efectos que causa depende de la relación entre la carga de fuego total y la superficie que delimita el espacio que arde.

Tomemos por ejemplo una carga de fuego que es capaz de liberar en total $10.000 \mathrm{Mcal}$ en un recinto de 100 $\mathrm{m}^{2}$ de superficie construida. El recinto mide $10 \mathrm{~m}$ de

Fig. 2

corresponde a la del ambiente. Un punto de soporte interior metálico visto o de la superficie de un soporte de hormigón (2), casi reproduce la anterior aunque con un ligero retraso que ocasiona temperaturas un poco más bajas en la parte ascendente y un máximo ligeramente desplazado. Si se trata de un soporte perimetral (3) del recinto incendiado, el retraso y disminución de temperatura respecto a la primera es mayor. En un punto interior de un soporte de fábrica, de hormigón, o de madera (4) la amortiguación es tan elevada que llegan a desdibujarse las inflexiones de la curva original. En los puntos opuestos de un muro de sectorización (5) se aspira a que no existan temperaturas que puedan ocasionar la ignición espontánea del local contiguo. En todos los casos el retraso significa además que, cuando la curva original decae, los elementos lo hacen más lentamente radiando al ambiente. La figura es meramente ilustrativa - no posee escala- y es una reconstrucción idealizada del autor a partir de las obtenidas por Arnault en ensayos a tamaño real. En la viñeta inferior, se dibuja a escala arbitraria la variación de la capacidad portante de un soporte interior cuya temperatura exterior sigue la curva (2). La (A) corres ponde a un material como el acero, que posee su mínimo valor al lle. gar a la temperatura máxima; al disminuir la temperatura la vuelve a recuperar. $\mathrm{La}(C)$ corresponde a un material como el hormigón cuya capacidad portante depende de una temperatura intermedia entre la exterior y el centro inatacado, por lo que su capacidad portante parece seguir las fluctuaciones de la curva (3). La (M) corresponde a madera seca, que se consume en el incendio perdiendo capacidad portante sin recuperarla luego. Deliberadamente los ejemplos están sim. plificados para mayor claridad. 
largo, $10 \mathrm{~m}$ de ancho y $3 \mathrm{~m}$ de alto. El calor que se emite actúa sobre toda la superficie perimetral del local, paredes, suelo y techo, en total $320 \mathrm{~m}^{2}$. En una distribución uniforme, corresponden $31 \mathrm{Mcal}$ agrediendo a cada $\mathrm{m}^{2}$ de dicha superfice envolvente. Si el local se compartimenta en cuatro - cada uno de ellos de $5 \mathrm{~m}$ de largo por $5 \mathrm{~m}$ de ancho-, en cada uno existe la cuarta parte de carga de fuego pero no la cuarta parte de superficie envolvente. Dado que ésta posee ahora $110 \mathrm{~m}^{2}$, corresponden sólo $23 \mathrm{Mcal}$ por $\mathrm{m}^{2}$ de superficie envolvente, y como este valor es inferior, la menor energía no puede sino conseguir calentar menos y alcanzar menos temperatura. Por el contrario, si existen tres recintos superpuestos de $100 \mathrm{~m}^{2}$ cada uno, la carga de fuego total es tres veces superior, pero en cambio si arden simultáneamente las tres plantas, el conjunto no posee triple superficie envolvente, sólo son $560 \mathrm{~m}^{2}$ en total. Ahora corresponden $53 \mathrm{Mcal}$ por $\mathrm{m}^{2}$ de superficie perimetral, y más calor significa poder alcanzar más temperatura.

Vemos así como la severidad del incendio depende de la evergadura del mismo. Es cierto que - a igualdad de todos los factores - la agresión a un elemento no depende de cuánto espacio arda, pero la cantidad de espacio que sufre simultáneamente incendio condiciona fuertemente el programa térmico resultante. Cuanto más espacio arde menos relación de superficie exterior construida existe, y si la carga de fuego es función de ésta última, las temperaturas alcanzadas son superiores. Una manera de recoger esta propiedad sería dar la repercusión de la carga de fuego no por $\mathrm{m}^{2}$ de superficie construida sino de la superficie delimitadora del espacio en el que se produce el incendio. Cuanto más pequeño sea éste, menor valor tendrá entonces la carga de fuego unitaria, indicando que la severidad del incendio va a ser menor.

Podemos adelantar pues por qué es aconsejable intentar que el incendio se desarrolle en el menor espacio posible. Cuanto menor sea, a igualdad del resto de factores, el incendio será menos severo, y más fácil resultará satisfacer los requisitos que demande.

La temperatura ambiente obtenida en el proceso anterior es la media en todo el espacio incendiado. Puede que la forma de la planta y la distribución de la carga de fuego permita suponer que en unas zonas puede ser algo superior, pero en términos generales es una buena aproximación tomar la media como representativa de los acontecimientos en todos los puntos de la planta. Pero no en alzado. La enorme entrada de aire fresco que significa el proceso de combustión completa -que exije del orden de 80 ó 100 renovaciones del total del volumen del espacio incendiado-, produce una estratificación importante de temperaturas. Los puntos inferiores del local están siempre mucho más fríos que los superiores, y, aunque la irradiación sea en todas direcciones, la temperatura resultante es diferen- te en suelo y techo. Casi se puede suponer que el incendio no afecta al suelo del local.

\section{Disipación de energía}

No toda la energia producida en la combustión de la carga de fuego es agresiva; parte de ella se disipa inocuamente. Una parte de la disipación ya ha sido considerada en el desarrollo del incendio, la que se va en los humos y gases de combustión. Hemos dicho que una entrada generosa de oxígeno origina un incendio muy vivo con altas temperaturas y duración corta; lo que ahora añadimos es que el gran volumen de renovaciones necesarias para ello circula a tanta velocidad que no tiene tiempo de transferir el calor a los elementos constructivos; buena parte de la energía se disipa en la atmósfera. Los peores incendios se producen con una aireación ni muy alta ni muy baja.

Otra energía inofensiva es la que se invierte en calentar los elementos secundarios interiores, como por ejemplo la tabiquería. Tal cuestión está relativamente poco estudiada, o se desprecia. Sin embargo calentar los tabiques de albañilería de una vivienda hasta 600 grados centígrados puede insumir cerca de la mitad de carga de fuego de la misma, por lo que los efectos perjudiciales del incendio pueden reducirse grandemente.

La energía que incide en las paredes y techos se capta en la superficie interior. Según aumenta su tempe ratura se transfiere calor de dentro afuera, y más tarde el elemento en cuestión radia hacia el espacio colindante. A bajas temperaturas radia menos que recibe y sigue calentándose; a altas puede llegar a radiar tanto como capta sin que aumente su temperatura. La cap tación depende de características del material, influyendo su color - capta menos el blanco-; la elevación de temperatura depende del calor específico del material; y la transmisión a su través depende de la conductividad térmica - un material muy aislante trans. mite poco y lentamente-.

Un cerramiento delgado, poco aislante y muy captador puede disipar al espacio exterior buena parte de la energía de la combustión quitando severidad al incendio. Por el contrario un cerramiento aislante - con mucha resistencia térmica - puede impedir la disipación, produciendo $\in$ el interior del edificio el efecto de horno, acrecentando la severidad del incendio y haciendo que sea más difícil y costoso soportar sus efectos.

Un cerramiento que posea una amplia capacidad térmica -es decir una gran masa y calor específicopuede no disipar pero sí absorber una gran cantidad de calor en elevar ligeramente su propia temperatura, restando también así gravedad al incendio. La peor combinación es un cerramiento con poca masa pero 
muy aislante. La mejor desde este punto de vista sería un cerramiento muy captador con alta conductividad.

Naturalmente lo anterior mitiga la severidad del incendio sólo si el elemento en cuestión no sufre con las temperaturas resultantes. Si su efecto es fundamentalmente disipador y posee poco espesor lo hará en régimen de bajas temperaturas, sin importancia. Si es fundamentalmente absorbedor, debe ser estable a altas temperaturas y sobre todo a diferencia de temperaturas en su interior.

Nos hemos referido a elementos de cerramiento - fachadas o cubiertas - ya que los elementos como paredes o forjados, que separan el espacio incendiado de otras zonas del edificio, no valen para disipar, y casi ni para absorber. En estos casos la energía que disipen la emitirian al espacio contiguo elevando peligrosamente su temperatura, y cuando alcance unos 200 grados centígrados la cara que radia, sería capaz de provocar la ignición, propagando el incendio en el local contiguo. La energía que absorbieran aumentaría su propia temperatura interior, pudiendo dañarlo y dando asimismo paso al incendio a su través. Los elementos que separan el espacio incendiado de otras zonas del edificio $-y$, naturalmente las zonas de fachada y cubierta próximas, que pudieran hacer de cortocircuito a la propagación del incendio- deben dotarse de las propiedades contrarias a las deseables para cerramientos. Es deseable que posean poca capacidad de captar energía, poca conductividad y, si se realizan con gran masa, con elevado calor específico y estabilidad a altas temperaturas.

Una de las mejores maneras de disipar energía es invertirla en cambios de estado. Elevar un grado la temperatura de un gramo de agua consume una caloria; evaporarla sin aumento de temperatura exige $j 360$ veces más! Por eso se utiliza agua para apagar el incendio; lo que hace es robar calor para evaporarse y bajar la temperatura del medio. La madera debe perder su humedad antes de arder, de forma que buena parte de las calorias que desprende se consumen en secar el resto. En la construcción convencional se usa con profu-

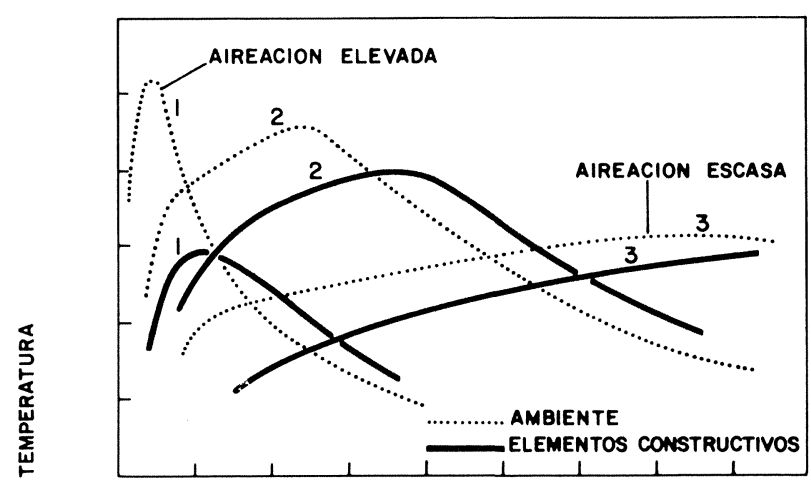

TIEMPO DESDE EL ORIGEN DEL INCENDIO sión el yeso. La deshidratación del yeso exige la liberación y posterior evaporación de más de dos moléculas de agua por cada una de sulfato cálcico. Este agua, integrada en tabiques y enlucidos, roba una cantidad importante de energía al incendio y mitiga sus efectos. No es fácil evaluar esta cuestión, pero, en los ensayos de fábricas, éstas salen sistemáticamente beneficiadas cuando poseen revocos de yeso, comparadas con las mismas soluciones en enfoscado de cemento.

La energía disipada inocuamente -e incluso la absorbida - puede tenerse en cuenta adoptando, para el estudio citado antes del desarrollo del incendio, valores de carga de fuego y ventilación más benignas. La nueva curva de evolución de temperatura ambiente, que tiene en cuenta la disipación, se toma como punto de partida para el análisis de incendio, tal como se establece a continuación.

\section{Análisis del incendio}

El análisis del incendio supone estudiar la evolución de las temperaturas en los elementos cuyo comportamiento pudiera ser relevante. No se consideran como tales los involucrados en disipación o absorción ya que se supone que no sufren por las temperaturas que alcanzan, o si son afectados, que su rotura es inofensiva. Si existe duda de esto, pueden volver a incluirse en el modelo, sin descontar la energía que disipan, y analizarse como cualquier otro elemento.

Cualquier elemento en contacto con el incendio sigue una evolución de temperatura que depende de la que existe en el ambiente incendiado. En cada instante se tiende al equilibrio de temperaturas transfiriéndose calor del punto caliente al frío; pero como la velocidad de transmisión es finita, ello conlleva un tiempo, de modo que en todo instante existe un retraso y diferencia entre los puntos que emiten y los que reciben calor. Así en las primeras fases del incendio la temperatura en las caras expuestas a fuego de todos los elementos son sistemáticamente inferiores a la del ambiente, y su máximo se produce después que aquél. Las cur-

Fig. 3

LA INFLUENCIA de la velocidad de aporte de oxigeno produce cam bios importantes en las curvas que describen la temperatura en el ambiente incendiado, representadas aquí en líneas de puntos. Para la alta velocidad de aireación que procuran unos amplios huecos, la curva (1) alcanza temperaturas elevadas y pequeña duración, con un má ximo acusado. Para aireación baja, el ascenso y descenso son lentisimos (3), alcanzando un máximo muy inferior pero una duración mucho mayor. Como en general, en los elementos constructivos la evolución de la temperatura representada de trazo continuo, sigue el desarrollo de la del ambiente con retraso, se suavizan enormemente los cambios bruscos, alterándose más cuanto mayor es la aireación. Tanto en el primer caso (1), como en el último (3) las temperaturas resultantes son bajas; los incendios más desagradables se dan con aireaciones intermedias. Las curvas se han tomado de figuras anteriores, dibujando para mayor sencillez sólo los tramos caracteristicos. 
vas que describen la temperatura en todo punto de un elemento constructivo se pueden entender como arrastradas por la del desarrollo del incendio.

Si el material tiene alto poder de captación térmica - caso del acero desnudo pintado de negro-, el retraso es leve, sólo debido al efecto de superficie, y la curva de temperaturas del elemento reproduce casi con todo detalle la del incendio. En general el retraso es apreciable, y eso significa máximos muy inferiores y el borrado de picos y brusquedades en una curva de seguimiento que parece atajar a la original. Es así como los incendios muy vivos con puntas de temperatura acusadas no logran transmitir esa variación por falta de tiempo, produciendo en los elementos diagramas de temperatura mucho más blandos, con consecuencias menos severas.

Si el material es muy conductor - caso del acero-, el calor captado se reparte casi instantáneamente a su través, originándose una distribución uniforme de temperaturas en todo momento. Si la superficie expuesta se reduce a la mitad, se capta sólo la mitad de energía y la temperatura resultante es menor. La evolución de la temperatura en este caso depende pues fuertemente de la relación de volumen del elemento a su superficie expuesta, en general expresable como relación de sección a perímetro expuesto, que podríamos denominar espesor medio - aunque es habitual encontrarlo tabulado como la relación inversa, ambiguamente expresado como factor de forma, con unidades y significado irreconocibles-. Si el espesor medio es pequeño, hay superficie captadora suficiente para calentar rápidamente toda la masa, y la evolución de temperaturas en el elemento reproduce casi exactamente la del incendio; si el espesor medio es muy grande, la entrada de calor está restringida y -aunque casi sin retraso-, la temperatura resultante es menor. Eso explica que los soportes metálicos desnudos en el interior de un recinto incendiado estén en situación comprometida mientras que el mismo soporte embutido en una medianería o en fachada, presentando sólo una cara al incendio, se vea muy poco afectado. También así se explica que los perfiles bajos de cada serie sean mucho más sensibles a fuego, y que los soportes en esquina o dando al exterior sean prácticamente inmunes al incendio.

Si el material es poco conductor - caso de madera, ladrillo u hormigón - la temperatura de la superficie puede ser la del incendio pero la de un punto interior resulta mucho menor, amortiguando enormemente las inflexiones de la curva ambiente. Eso explica que dichos materiales sobrevivan en el incendio ya que poseen una temperatura media inofensiva o un núcleo inatacado. Naturalmente siguen siendo más sensibles los elementos de sección pequeña y los que reciben el fuego por todos lados. Para la mayoría de los propósitos es co- mo si el incendio penetrara una profundidad dada según la temperatura exterior alcanzada.

Cuando la temperatura del incendio pasa a disminuir, la situación es inversa. La dificultad en captar se convierte ahora en dificultad para emitir. Cuando baja la temperatura del incendio, los elementos calentados con retraso llegan a poseer temperaturas superiores a las del incendio, y alargan su régimen de temperaturas un tiempo más largo, que no es sino una propiedad de una curva arrastrada por otra: el retraso en seguirla lo es también en el descenso. Si el elemento reprodujo casi exactamente la subida, sigue reproduciendo fielmente la bajada, sin retraso ni superarla apenas en temperatura. Si el elemento se resistió a ser calentado por el aire, se refrigera también con dificultad, dando lugar a una curva que en muy poco recuerda la del incendio. Aunque casi nunca pueda tener relevancia, conviene recordar que la energía que antes computábamos como absorbida se devuelve ahora al sistema, alargando la duración real del incendio.

Para el análisis del incendio tenemos que contar con los diferentes modelos que, de cada material constructivo, existen en la literatura especializada, aunque el nivel de tratamiento es poco homogéneo.

\section{Capacidad térmica}

El modelo de análisis a incendio debe además tener en cuenta la capacidad térmica de lo que eleva su temperatura; esa elevación roba calor al incendio.

Los modelos simplificados analizan un elemento bajo un programa térmico supuesto obteniendo su temperatura pero en la hipótesis de que la fuente de calor es inagotable y mantiene tercamente la temperatura. Si estudiamos un soporte aislado en un espacio grande se puede aplicar el modelo simplificado sin corrección, pero si se trata por ejemplo de un polideportivo cubierto con una celosía espacial, el seguimiento instantáneo de la temperatura del incendio por todos los tubos de la cubierta supone un consumo notable de energía que reduce automáticamente la temperatura supuesta del incendio y con ello la de la propia estructura analizada.

Un procedimiento sencillo de evaluar la importancia de este fenómeno es quitar de la carga de fuego la necesaria para calentar al valor esperado los elementos analizados y ver lo que sucede. En el caso de elementos puntuales como vigas o soportes de una estructura convencional, probablemente será una energía despreciable, pero con los forjados, muros o losas puede ser muy diferente. El calentamiento de forjados convencionales hasta una -inofensiva - temperatura de $600^{\circ} \mathrm{C}$ puede detraer la tercera parte de la carga de fuego en un edificio de viviendas. 


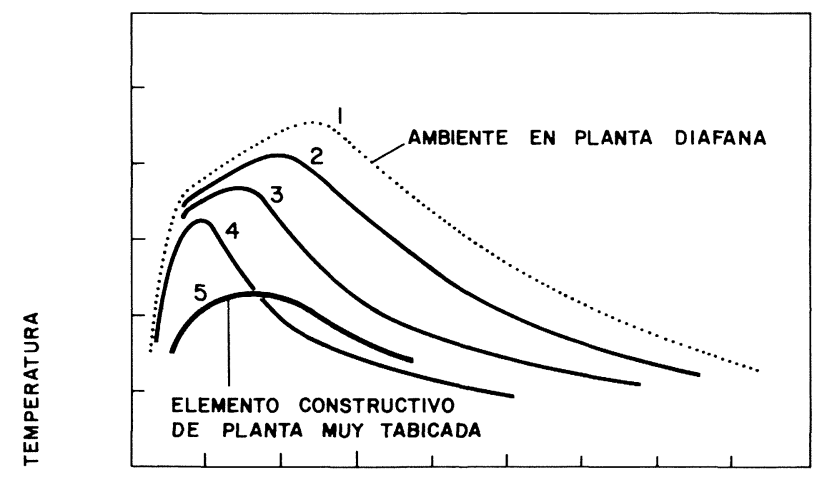

TIEMPO DESDE EL ORIGEN DEL INCENDIO

LA INFLUENCIA de la absorción de energía por parte de elementos secundarios como tabiquería o en algunos casos forjados puede influir notablemente en la severidad del incendio. En planta diáfana(1),
Fig. 4

sin elementos que absorban energía, la evolución de la temperatura ambiente es la teórica, que aquí corresponde de nuevo al caso anterior de carga y ventilación medias. La existencia de tabiques obliga en cada punto a descontar como carga de fuego la necesaria para elevar la masa de éstos a esa temperatura, y a rehacer el cálculo -iterativamente - hasta que ambas cantidades coincidan, o a plantear las ecuaciones consiguientes. Con tabiquería ligera (2) se consigue rebajar muy poco el máximo de temperatura y las temperaturas de la fase de decaimiento del incendio. Con tabiqueria ordinaria (3) la reducción de carga de fuego puede ser en viviendas de una tercera parte, rebajando sustancialmente temperatura máxima y duración del incendio, y por lo tanto su severidad. Cuando, como en viviends unifamiliares, sea preciso considerar el incendio simultáneo de varias plantas, la masa de los forjados intermedios también consume energía (4), disminuyendo aún más la severidad del incendio. El retraso y reblandecimiento de la curva ambiente que supone su paso a cualquier elemento constructivo hace que la curva efecto (5) elimine casi completamente toda su agresividad potencial. La figura, meramente ilustrativa - sin escala - se ha obtenido a partir de las anteriores.

(Entre paréntesis habría que indicar que el incendio simultáneo en toda una zona no es necesariamente la peor hipótesis para algunos elementos y es poco realista. Para la estructura puede ser peor una agresión térmica localizada en un soporte que dilata diferencialmente y altera profundamente las solicitaciones, que un incendio generalizado que no tiene influencia en el análisis estructural al dilatar por igual todos ellos.)

A partir de las características térmicas de los materiales constructivos - como captación o emisividad, calor específico y conductividad-, se obtienen las temperaturas alcanzadas en estos elementos no sólo en la superficie expuesta sino en todo su interior, teniendo en cuenta, si es importante, la energía que detraen para ello.

La comprobación de los resultados del análisis debe considerar en primer lugar si los elementos que separan el espacio incendiado del resto del edificio permiten el paso del incendio a su través, lo que se supone que sucede al menos cuando en la cara no expuesta se alcanza una temperatura crítica, en torno a $200^{\circ} \mathrm{C}$. Si esto se produce, o bien se rehace el análisis - anexionando el local contiguo - o se intenta disminuir la severidad del incendio -opción obligada cuando el espacio contiguo corresponda a otro usuario o a otro edificio-. Si no se alcanza esa temperatura crítica, ni los elementos se agrietan, ni dejan pasar humos ni gases, la hipótesis de incendio es correcta: el incendio no sale de la zona supuesta. Se dice entonces que el espacio estudiado se comporta como un sector de incendio, y que dichos elementos de sectorización poseen suficiente resistencia a fuego.

Si el fallo de cerramientos o cubiertas puede afectar a la evacuación, producir víctimas, o permitir la propagación del incendio, se debe o bien dotar a estos elementos de la suficiente resistencia a fuego para impedir su fallo, o disminuir la severidad del incendio. 
Si las temperaturas resultantes en los elementos estructurales no permiten que éstos cumplan con su papel, debe entenderse que la estructura colapsa. Si este fallo no compromete la evacuación, ni puede causar víctimas, ni permite la propagación del incendio, ni afecta a otros edificios, son consideraciones económicas las que indican lo que debe hacerse: permitir el colapso, aumentar la resistencia o disminuir la severidad -solicitaciones-del incendio. El colapso es un lujo que casi sólo puede permitirse cuando se trata de una edificación exenta, de una planta, pero es importante tenerlo en cuenta.

Para disminuir la severidad de un incendio hay que actuar sobre los factores que la determinan. La carga de fuego disminuye con el tamaño de sector, y ello se traducirá siempre en menos solicitaciones para todos los elementos. La temperatura máxima puede reducirse quitando o empequeñeciendo huecos aunque esta opción aumenta la duración del incendio. Si es prioritario reducir la duración y existe margen para soportar un ligero aumento de temperatura, puede hacerse lo contrario: prever grandes huecos al exterior, y sobre todo, si se puede, en techo.

Lo característico de las paredes exteriores y cubiertas es su capacidad de disipación, de emitir el calor que les llega. Una alta resistencia térmica o aislamiento es perjudicial. No tiene sentido preocuparse ni aumentar la resistencia a fuego de fachadas. Por el contrario, lo que importa - salvo los puntos próximos a acometida de elementos de sectorización-, es que posean la menor resistencia a fuego posible.

Lo característico de la tabiquería y obra interior, incluidos los forjados, es su capacidad térmica. Resulta recomendable elegir los que exigen una gran cantidad de calor para elevar su temperatura, siendo muy favorable la presencia de productos que incluyen agua, como el yeso.

Lo característico de los elementos de sectorización -que en muchos casos incluye también los forjados-, es su resistencia térmica, la capacidad de no calentarse demasiado y no emitir al sector colindante. Desgraciadamente mejorar su comportamiento es bajar la disipación, confinando el incendio y aumentando su severidad.

Lo característico de la estructura es su resistencia, la capacidad de soportar grandes temperaturas y largo tiempo sin fallo. Aumentar la resistencia de la estructura es siempre ventajoso, no tiene contraindicaciones. La resistencia de la estructura mejora sobredimensionándola, o disponiendo las piezas más afectables tras un elemento de protección.

\section{Confinar, disipar y sectorizar}

Entre confinar y disipar debe primarse lo segundo. Si se disipa no hay por qué resistir; si se confina el incendio no hay más remedio que resistirlo. Sólo cuando no sea posible la disipación - porque ésta atacaría a otro usuario-, debe intentarse confinar el incendio. Bien es verdad que confinando y sectorizando más se reduce la severidad por un lado, pero el intento de que las paredes límites del sector impidan la propagación del incendio hace que la agresión se vuelva hacia el interior con el desagradable efecto horno antes mencionado, exigiendo más resistencia por otro. No es fácil establecer cuándo es preferible aumentar carga de fuego y tamaño de sector compensándolo con elevada disipación, o al revés, optar por sectores menores, encajonados y sin casi disipación, pero con carga de fuego más baja. La alternativa debe estudiarse en cada caso concreto.

Si se opta por disipar - la opción más razonable en naves y edificios de una planta o de varias ampliamente comunicadas entre sí-, para que la estructura portante siga en pie no será casi necesaria resistencia a fuego por su parte. No hay contradicción en ello, ya que la pequeña energía restante no será capaz de elevar sustancialmente la temperatura de la estructura. Este tipo de edificios pueden ser seguros sin necesidad de resistencia a fuego: no existiendo solicitación, la resistencia puede ser bajísima, sin afectar a la seguridad.

En edificios de pisos hay una sectorización insinuada en los forjados que puede completarse fácilmente con tabiques o muros especialmente resistentes, aunque ello implica dotar también de resistencia a casi toda la fachada y con ello eliminar buena parte de su capacidad de disipación. En el caso de viviendas la separación entre éstas suele conferir suficiente sectorización en los términos que aqui se manejan, es decir, que el incendio que se declara en una de ellas raro es que se propague a otra a través de la medianería común.

Al revés que en naves, en los edificios de pisos se está prácticamente abocado a sectorizar, y a sobrevivir por resistencia y no por disipación. Lo que conviene entonces es conseguir sectores del menor tamaño posible. Si resulta obligado tratar el conjunto de varias plantas como un solo espacio incendiado o sector, la absorción de energía que necesitan los forjados para calentarse compensa parcialmente el aumento de carga de fuego unitaria que supone esa hipótesis.

$\mathrm{Si}$, supuesto un espacio incendiado, el análisis exige la necesidad de anexionar un espacio contiguo por la debilidad resistente del elemento que los separa, generalmente se aumenta carga de fuego a más velocidad que superficie envolvente. Los dos espacios juntos poseen una relación de superficie envolvente a vo- 
lumen interior más baja, produciéndose un incendio de severidad aún mayor, lo que incrementará las posibilidades de que el nuevo incendio a estudiar traspase con más facilidad sus actuales límites, en una espiral que puede hacer que, hasta que no se considere todo el edificio incendiado simultáneamente, no se llegue a una hipótesis coherente. $Y$ un incendio de esa envergadura y severidad planteará una agresión térmica y unas solicitaciones casi imposibles de resistir.

Pero para considerar que el incendio afecta simultáneamente a sólo una zona, será preciso confirmar además que los huecos de comunicación con el resto del edificio posean puertas que no pueden quedar abiertas inadvertidamente y que cumplen los requisitos mencionados anteriormente para lo que sectoriza: no dejar pasar las Ilamas, ni el calor, ni humos.

En esta cuestión existe algún margen de tolerancia. Siempre que el tamaño relativo de la puerta -o hueco de comunicación, que también puede hacerse este razonamiento para los de escaleras - sea muy inferior a la superficie de separación de las dos porciones de edificio, se puede razonar como si el incendio no pudiera pasar libre e instantáneamente del sector incendiado al comunicado con él. La existencia de una puerta poco resistente, o un hueco, puede que no sectorice en el sentido de confinar el incendio en un espacio restringido, pero sí lo puede ser en el sentido de hacer que no sea simultáneo en todo el conjunto. Tal cuestión, delicada de adoptar, la suelen recoger los reglamentos, exigiendo a las puertas menos condiciones que al muro en la que están recibidas, siempre en la suposición de que suponen una fracción pequeña de superficie en el conjunto del elemnto sectorizador. Para el análisis podría tratarse como dos incendios diferentes retrasados uno respecto al otro: el incendio real sería de más amplitud, pero no de más envergadura; para la agresión a los elementos constructivos sería como dos incendios sucesivos, generalmente no más peligrosos que cualquiera de ellos por separado.

\section{Vía analítica vs, vía experimental}

El modelo analítico anteriormente expuesto presenta las variables pertinentes al fenómeno del incendio en los edificios, cómo y sobre qué operan, y puede servir para interpretar correctamente todo tipo de datos que puedan influir, pero tiene lagunas en su formulación que no permiten aplicarlo en muchos casos.

Hay disponibles valores relativamente fiables de cargas de fuego para edificios de usos domésticos, pero no es tan fácil computar los de revestimientos y estructura. Los coeficientes $m$ para corregir la carga de fuego según su velocidad de ignición sólo son aproxima- dos, no incluyen muchos casos habituales, y además sólo permiten hacerlo cara a la obtención de temperatura máxima y no cara a la duración de incendio. Los modelos de desarrollo de fuego sólo incluyen espacios simples, con incendio rigurosamente simultáneo en todo su volumen, no directamente aplicables a edificios reales, con envolturas homogéneas y sin elementos en su interior, no incluyen disipación variable, y no tienen en cuenta la absorción de los elementos secundarios ni la de la propia estructura.

No está formulado tampoco cómo se propaga el incendio por un sector profusamente tabicado, y qué impedimento en la propagación del incendio supone cada elemento del edificio, como por ejemplo pudiera ser un amplio vestíbulo de material incombustible y con gran capacidad térmica.

Además, aunque en algunos casos - como en elementos estructurales-, podemos calcular cómo se comportan ante la agresión térmica obtenida con el modelo analítico, en general no sabemos cómo continuar.

No existe un modelo que nos diga cuándo en cada programa térmico se cuartea una fábrica de ladrillo y deja de poseer las características funcionales que se le exijen. Más desamparados estamos aún en el caso de carpinterías, conductos, u otros elementos constructivos.

Además, en los materiales que cooperan activamente al incendio, situados en puntos cruciales, como son los de revestimiento en caminos de evacuación, o los de decoración en salas abarrotadas de público, hay características adicionales que es necesario tener en cuenta, como las de capacidad de propagar la llama, emanación de gases, su opacidad, velocidad de inflamación, etc., imposibles de recoger en el modelo analítico expuesto. Tales características se contemplan en la llamada reacción a fuego de los materiales de acabado.

Como alternativa al modelo analítico no vale sino el experimental. Si fuéramos capaces de realizar todas las operaciones del modelo analítico, y no supiéramos contestar a la pregunta de si un determinado elemento constructivo responde adecuadamente, bastaría someterlo experimentalmente al programa térmico obtenido en el ahálisis.

Esto es demasiado complejo. Sería como intentar confirmar la bondad resistente de una fábrica probándola para la carga de cada obra; es preferible obtener algún indicador de la solicitación que actúa en cada caso y compararla con el valor correspondiente de resistencia del material, a partir de un ensayo tipificado. En nuestro caso se necesitaría caracterizar el incendio en el edificio mediante un valor de solicitación y compararla con el de resistencia a fuego de cada elemento obtenida mediante un programa térmico normalizado. 


\section{Ensayo de resistencia}

Determinar un ensayo diferente para cada tipo de incendio obligaría a obtener la resistencia a fuego tras múltiples y diferentes pruebas de ascenso y descenso térmico, ya que no hay una gradación de incendios en la que cada uno de ellos englobe a los demás. En Resistencia de Materiales -y también en otros campos - el ensayo de resistencia se limita a probar con una escala creciente de solicitaciones y caracterizar la resistencia con el último valor que se alcanza sin fallo.

La simplificación que supone este planteamiento es sugerente, y siempre existe la opción de que, si se sabe de antemano cómo va a ser la prueba de constatación de resistencia, los resultados del análisis se expresen en términos de dicha prueba. El inconveniente de una formulación de este tipo es que la manipulación de los resultados del análisis para adecuarlos a la comparación con el procedimiento normalizado resta significado físico y hace ininteligibles los resultados. Esta alternativa supone estudiar la posibilidad de un único programa térmico que, pasando por todos los grados de agresión, permita caracterizar la resistencia a fuego de los elementos.

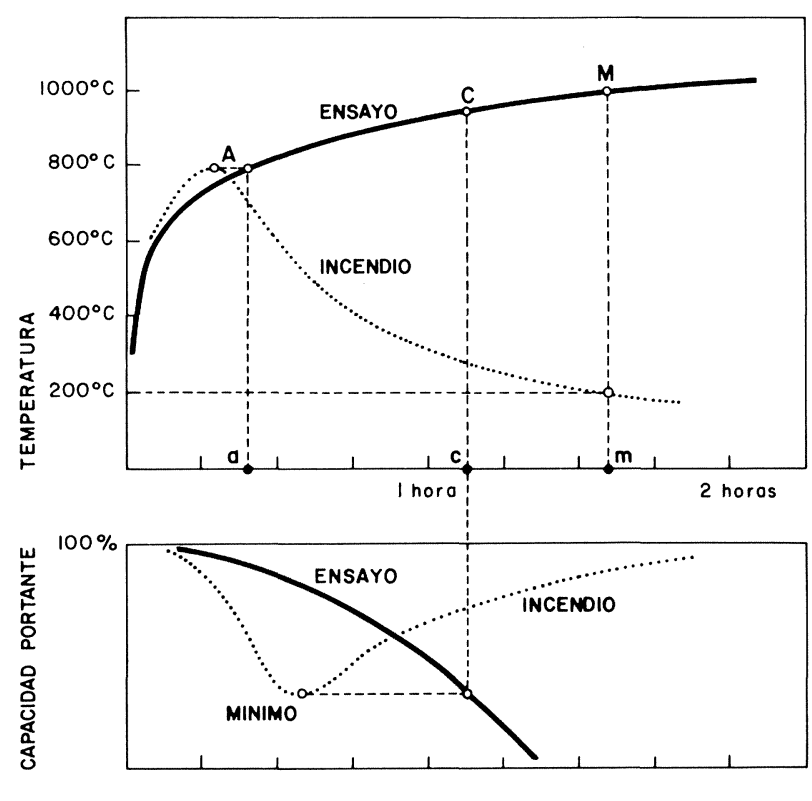

TIEMPO

LA CURVA NORMALIZADA de ensayo de resistencia se representa en la curva continua. Nótese su gran similitud con la parte ascendente de la temperatura ambiente de los incendios para una aireación in. termedia, por lo que puede corresponder al crecimiento de tempera. turas en una planta tipo usual. Cada punto de la curva se corresponde con el máximo alcanzado en el incendio para una carga de fuego dada. En parte por la dificultad del ensayo, y en parte porque esa misma dificultad existe en el incendio, se tarda mucho más en aumentar la temperatura cuando ésta ya es alta que en los primeros momentos, cuando es baja. La curva no posee la rama descendente clásica
En los ensayos de resistencia de materiales la realización del ensayo pasando por tadas las cargas conlleva una duración. Primero por problemas físicos: no se puede alcanzar cualquier valor de carga instantáneamente, la máquina de ensayo necesita un tiempo para ello. Segundo porque un ensayo instantáneo prueba otra característica física distinta y altera la respuesta buscada. A fuego sucede algo parecido, siendo preferible que el trámite de pasar por todos los grados de agresión se realice en tiempo comparable a la velocidad real.

En la actualidad se intenta expresar la capacidad resistente de los elementos a fuego mediante la prueba térmica con una curva normalizada de temperaturas. Dicha curva reproduce con relativa similitud el ascenso de temperaturas que se presenta en plantas de pisos con ventanas que poseen en total un tamaño como entre un sexto y un octavo de la superficie útil del local, pero no tiene grandes coincidencias con lo que sucede en otros casos. Cada punto de la curva normalizada corresponde a la máxima temperatura alcanzada para cada valor de carga de fuego unitaria: hacia los $800^{\circ} \mathrm{C}$ corresponde a edificios de baja carga de fuego como las escuelas; a $900^{\circ} \mathrm{C}$ los de carga de fuego media como los hoteles o viviendas, y valores aún más elevados a cargas de fuego como las que se encuentran en algunas oficinas, comercios o almacenes.

de los incendios reales (uno de los cuales se representa de trazos y sirve de base para los comentarios siguientes). Esa diferencia es el precio que se paga por la ventaja de tener un único programa térmico que pase por lo que se consideran severidades crecientes: diferentes tiempos desde el origen. La simplicidad y el eclecticismo de esta curva dificulta la interpretación de cómo es capaz de representar la agresión del incendio. Un punto como el (A), correspondiente a carga de fuego moderada, se alcanza en 25 minutos pero representa un fuego de duración de más de tres horas. (La curva de trazos del incendio se ha dibujado algo separada para mejorar la legibilidad de ambas).

Un soporte de acero bastaría someterlo a un tiempo de ensayo hasta el punto (A) para reproducir la severidad del incendio, ya que para acero lo relevante es la temperatura: el tiempo equivalente exigible al soporte metálico seria el valor "a". Como para madera lo decisivo es la duración del incendio, el ensayo debería llevarse hasta el punto (M) para reproducir la severidad del incendio: el tiempo equivalente exigible al soporte de madera es el valor " $m$ ". Para un material como hormigón se representa en la viñeta inferior, a escala convencional, en trazo continuo la gráfica de capacidad resistente en el ensayo, $y$, de trazos, la misma variable ante el incendio de la viñeta superior. Se ha dibujado la forma de encontrar el punto $(C)$ del ensayo que reproduce la severidad del incendio: para hormigón el tiempo equivalente exigible es el valor "c". En los otros dos materiales anteriores se debería haber procedido con una construcción similar, a partir de los diagramas de capacidades resistentes de una figura anterior; la simplificación adoptada para el acero, por temperatura, y para madera, por tiempo, es artificial, pero ilustrativa de los casos extremos. Los valores " $a$ ", " $m$ ", y " c " no están representados a escala pero presumiblemente si están en orden en los casos usuales de edificación. La ley de disminución de resistencia del hormigón se explica en el texto. La figura está tomada del borrador del Código Modelo de Hormigón, Boletin, 174-1987. 
El tramo entre el origen y cada punto se asemeja al régimen de temperaturas de la rama ascendente de incendio con la carga de fuego correspondiente a dicho punto: asi se tarda unos 25 minutos en alcanzar 800 grados centígrados - más o menos lo que sucedería en un aula tipo-, y 40 minutos en alcanzar $900^{\circ} \mathrm{C}$-también más o menos lo que se tarda en el modelo de incendio aplicado a una vivienda tipo-. Como en los incendios reales el aumento de carga de fuego no consigue elevar proporcionalmente la temperatura - aunque dilata muchísimo el tiempo para alcanzar la máxima - la curva normalizada ralentiza su ascenso, tardando 100 minutos en alcanzar $1000^{\circ} \mathrm{C}$, que para aireaciones usuales exige una carga de fuego cuádruple de la de una vivienda convencional, y los $1200^{\circ} \mathrm{C}$ se alcanzan hacia los 360 minutos de ensayo, que en la realidad no se consigue - con más aireación - ni con cargas de fuego diez veces superiores a las de vivienda.

La primera diferencia, notable, con las curvas obtenidas en el análisis de los incendios, es que la curva normalizada no posee rama descendente. En un aula tipo se tardan tres horas en descender de los $800^{\circ} \mathrm{C}$, en una vivienda tipo se tarda casi cinco horas en bajar de los $900{ }^{\circ} \mathrm{C}$, y si el incendio alcanza $1000^{\circ} \mathrm{C}$ es probable que tarde en reducirlos unas ocho horas. Como existe una cierta relación entre los tiempos de ambas ramas, y para muchos propósitos lo que importa es la temperatura máxima, ello no constituye mayor problema.

Dado que se trata de una curva, cada punto puede venir descrito por el tiempo o por la temperatura; así los grados de resistencia necesaria en los casos anteriores se expresarian como $800^{\circ} \mathrm{C}, 900^{\circ} \mathrm{C}, 1000^{\circ} \mathrm{C}$, o como 25 minutos, 40 minutos, 100 minutos.

Parece haber consenso en utilizar lo segundo; desgraciadamente desde nuestro punto de vista. Los resultados de ensayos de resistencia de materiales no se expresan en tiempo sino en carga, y en fuego tanto o más representativa es la temperatura que el tiempo. Utilizar un único patrón de medida será ajustado para unos materiales, pero injusto -en el sentido de no ajustado- con otros. De acuerdo con lo dicho al principio, expresar las cosas en tiempo tendrá sentido para la madera, pero no para acero; tomar la otra alternativa tendrá los efectos contrarios. Para hormigón o fábricas ninguna de las dos es atinada, pero como en general son muy resistentes a fuego no acusan el problema.

A nuestro juicio el inconveniente más grave del ensayo normalizado, que no permite utilizarlo universalmente, es que la escala de agresiones es en temperatura. No se programa la combustión de una determinada carga de fuego sino que el ensayo mantiene a cualquier costo la temperatura. $Y$ en ese sentido no es capaz de dar respuesta significativa a algunas situaciones. El ensayo de resistencia mecánica no puede aplicarse al agua por las buenas: da resistencia nula.

El agua es un fluido perfecto que no soporta nada de compresión uniaxil aunque soporta compresiones. La validez y universalidad del ensayo de carga uniaxil se basa en su sencillez y en que la mayoria de los materiales no son fluidos perfectos, y en que los resultados de compresión uniaxil reflejan bastante bien sus demás comportamientos.

Lo mismo pasa con el ensayo normalizado de fuego. Si rodeamos el horno con un material que sea un conductor perfecto, el ensayo no dice nada; por mucho calor que robe, el horno siempre quiere remontar la temperatura, siendo un manantial inagotable de calor: juntar un suministrador incansable con un devorador insaciable ofrece resultados imprevisibles. Para conocer la resistencia del agua es menester acudir a otro ensayo; para saber la resistencia a fuego del acero - un conductor casi perfecto-, es posible que también fuera mejor un ensayo diferente. $Y$ así como el agua empaquetada en un bidón puede ser ensayada normalmente - aunque la resistencia resultante corresponde al sistema agua + bidón-, también puede utilizarse el ensayo normal para acero con revestimiento o dentro de un muro - aunque la resistencia que se obtiene corresponde al sistema perfil + revestimiento-. Pero al llegar a espesor de recubrimiento nulo y a bidón de espesor nulo los dos procedimientos fallan. Como el horno se empeña - por convenio- en producir y alcanzar en todo su interior una temperatura de $600{ }^{\circ} \mathrm{C}$ en 7 minutos y de $700^{\circ} \mathrm{C}$ en 12 minutos, por convenio también el acero no posee casi ninguna resistencia a fuego, y es falso.

El incendio del aula que tomábamos antes como referencia alcanza $800{ }^{\circ} \mathrm{C}$ en 25 minutos en el ambiente, no en los soportes. Aunque el ensayo reproduzca con fidelidad el efecto de superficie y el de espesor medio, no permite reflejar los demás fenómenos. Procesando el modelo en el que no hay un manantial inagotable de energía, un soporte desnudo en el interior del aula anterior muy bien podría alcanzar sólo $700{ }^{\circ} \mathrm{C}$ de temperatura máxima, y $650^{\circ} \mathrm{C}$ si está en fachada presentando sólo una cara al fuego, y con sólo centímetro y medio de enlucido de yeso la temperatura máxima superaría escasamente $300^{\circ} \mathrm{C}$. Aun con $700^{\circ} \mathrm{C}$, si el soporte posee muy poca carga -o lo que es lo mismo, posee mucha más sección que la estricta-, es perfectamente capaz de resistir.

No obstante, estos inconvenientes siempre pueden obviarse, si, como decíamos antes, la solicitación se expresa en términos que suponen que la comprobación va a realizarse con una determinada curva. 


\section{Solicitaciones del incendio}

Con objeto de comprobar si cada elemento es capaz de soportar el incendio previsible, contando con que su capacidad está expresada en términos del punto más elevado que alcance en la curva normalizada de ensayo, hay que valorar la agresión del incendio sobre el elemento en la situación que posee dentro de la construcción. Eso significa dar el punto de la curva de ensayo que equivale a la agresión real que sufre el elemento. No es fácil esa traducción, que es tanto como responder a la pregunta: equivalente ¿en qué?

Sigamos razonando con el ejemplo del aula del apartado anterior. Si el incendio previsible es capaz de llegar a una temperatura ambiente de $800^{\circ} \mathrm{C}$ en 25 minutos, para descender a temperatura ordinaria en otras tres horas más, ¿cuál es el punto de la curva normalizada que representa la severidad de ese incendio? Ya sabemos que la respuesta no es única; depende del material en cuestión.

En madera la agresión térmica depende casi sólo de cuánto tiempo supera el incendio $200^{\circ} \mathrm{C}$. En el ejemplo, el incendio atacaría a un soporte de madera durante más de tres horas. ¿Debería decirse que la resistencia a fuego exigible es tres horas, o 25 minutos? 0 dado que en las tres horas las temperaturas son mucho más elevadas que las del incendio previsible, ¿debería comportarse bien durante un tiempo algo inferior a tres horas?

En acero lo que explica su fallo es la temperatura máxima; ésta se alcanza teóricamente en el ejemplo en 25 minutos. ¿Sería necesario un soporte que en el ensayo se comportara bien durante los primeros $25 \mathrm{mi}$ nutos? o ¿habrá que considerar las variables de disipación y absorción, planteando como solicitación de incendio un valor menor? Si el acero dimensionado estrictamente falla - dicho de manera muy burda- entre $600^{\circ} \mathrm{C}$ y $700^{\circ} \mathrm{C}$, muchas de las estructuras desnudas de acero en cubiertas de naves, polideportivos, con cargas de fuego bajas, y ventilaciones y disipaciones altas, que probablemente soportarán bien el incendio en su interior, analizadas, y traduciendo la temperatura resultante a tiempo, éste tendrá que ser inferior a 7 minutos, que es cuando en el ensayo se llega a esas temperaturas. Para comprobar dichas estructuras ¿bas taría que soportaran el ensayo menos de 7 minutos y esto explicaría que soportan un incendio que dura tres horas?

En hormigón lo que explica su fallo, es, de una manera harto simplista, en cuántos puntos se alcanza más de $500^{\circ} \mathrm{C}$. En el ejemplo, a los 25 minutos se alcanza en el ambiente -y en la superficie del hormigón ya que es muy poco conductor- $800^{\circ} \mathrm{C}$; apenas un centímetro de profundidad al interior del soporte la temperatura ya es inferior a $500^{\circ} \mathrm{C}$ : conclusión, el soporte ve mer- mada su sección tan poco que aguanta perfectamente. Cuando la temperatura empieza a descender en el incendio también lo hace en la superficie del soporte, pero en su interior el calor sigue propagándose hacia el centro. La curva de temperaturas del incendio pasa de nuevo por $500^{\circ} \mathrm{C}$ media hora más tarde y el soporte recupera dicha temperatura en la superficie; la temperatura máxima está ahora en el interior del soporte que simultáneamente radia hacia dentro y hacia afuera. ¿Cuál es el punto del ensayo que representa la peor situación del soporte?, probablemente ninguno; existe uno que representa una situación equivalente en fracción de sección a más de $500^{\circ} \mathrm{C}$, pero no en la temperatura del acero de armar que puede colaborar decididamente en la resistencia. Sólo podemos asegurar que el punto equivalente es superior a 25 minutos e inferior a hora y media, difícil de estimar, y dependiente de la cuantía de armado, del recubrimiento a las armaduras, de si predomina la compresión o el momento flector, etcétera.

No se crea que los anteriores planteamientos son exclusivos de las estructuras; con fábricas, muros de sectorización, o puertas sucede lo mismo. El valor de solicitación a fuego supone encontrar un punto de la curva normalizada tal que el ensayo hasta ese punto suponga una agresión equivalente a la del incendio real, y la cuestión sigue siendo ¿en qué equivalente? Porque una puerta de madera sufre el incendio de muy distinta forma que una de acero, de lo que se deduce que la solicitación correspondiente a un incendio dado no existe independientemente del material de la puerta: es distinto en madera que en acero. La pregunta de cuál es el punto del ensayo que traduce la severidad de un incendio dado no tiene respuesta.

Con lo expuesto puede entenderse cuáles son las complicaciones y los manejos que debe hacerse en la solicitación para expresarla en términos de la curva normalizada. Los valores convencionalmente seguros de solicitación -o resistencia exigible- de que disponemos, definidos en términos de la curva normalizada, como RF-30, RF-60, RF-90, etc., no son transparentes, y como tal nos resistimos a expresarlos en ninguna unidad física.

En un aula como la del ejemplo es usual exigir como seguro un soporte RF-90. Lo único que eso significa es que se supone que si se dispone en el aula un soporte que sale airoso del ensayo hasta el punto definido por 90 minutos $/ 986^{\circ} \mathrm{C}$, soportará sin daños la agresión del incendio real que es previsible que se produzca en el aula. Pero nada más; ni el incendio alcanzará $986^{\circ} \mathrm{C}$, ni durará 90 minutos, ni el valor 90 puede utilizarse para ningún otro propósito, ni tiene significación real de tiempo.

El valor de solicitación detrás de las siglas RF es sólo un tiempo equivalente en la comparación de la integra- 
ción de los procesos de incendio real y ensayo. Expresar la solicitación a fuego, en tiempo de una curva de temperatura, es una gran simplificación, demasiada quizá; su extremada sencillez acarrea serias incoherencias. Desgraciadamente la equivalencia entre el tiempo de ensayo y la agresión del incendio no puede ser igualmente cierta simultáneamente para acero, madera u hormigón, ni correcta independientemente de la capacidad de disipación, de absorción, del material de paredes y techos, y mucho menos de variaciones de carga de fuego significativas que puedan darse. Incluso depende de la forma de la sección, del espesor de las chapas, de la cuantía de armado, de demasiadas cosas. Decir que un incendio es tan severo como lo que se produce en el ensayo no aclara mucho de lo que se quiere expresar. Pero hoy por hoy no tenemos nada más.

\section{Estado de la cuestión}

En realidad sí tenemos algo más. Aun con sus lagunas, y sus deficiencias de formulación, el modelo analítico permite en algunos casos realizar cálculos transparentes; el modelo analítico permite en algunos casos realizar cálculos transparentes que posibilitan elegir resistencias adecuadas a las solicitaciones que causa el incendio, y elegir combinaciones favorables de las variables esenciales.

Con el modelo analítico, en el aula del caso que hemos tomado como ejemplo, se obtendría una temperatura ambiente máxima que no llega a $800^{\circ} \mathrm{C}$, y que sería reproducible en el ensayo a los 25 minutos. Un soporte de acero que aguantara 25 minutos de ensayo bastaría. Un soporte de acero RF-25 sería suficientemente seguro.

Si queremos progresar en la racionalización de este tema y alcanzar niveles homogéneos de seguridad, como valor de solicitación a fuego - de resistencia exigible-, debería proveerse un valor dependiente al menos de todas las variables antes citadas: un uso bien definido, un tamaño y forma de sector, un tamaño de huecos, y una composición de los elementos constructivos.

Pero con objeto de poder utilizar el resultado contra el valor proveniente del ensayo normalizado, la evaluación de la solicitación debe depender además del material, dimensionado y organización del elemento. Es decir que la solicitación en un determinado sector de un edificio será distinta por ejemplo, según tengamos que aplicarla luego a un soporte de hormigón o a uno metálico; éste es quizá el aspecto más chocante del método del tiempo equivalente: que el riesgo en un edificio se exprese como una resistencia necesaria de 100 minutos si el soporte es de madera y sólo 25 minutos en acero repugna algo. Pero no hay opción; ya decíamos al principio que no se puede describir la severidad del incendio con un sólo valor independientemente del elemento que se trate. Mantener el planteamiento de expresar la resistencia en términos de la curva normalizada, y reconvertir el método analítico en tiempo equivalente no nos parece satisfactorio. Quizá expresar la solicitación y la resistencia a fuego en temperatura en vez de en tiempo solucionaria algo.

El modelo analítico debiera ser sensible además a algunas variables tradicionalmente recogidas en las tablas de valores convencionalmente seguros. La altura del edificio o el valor social del mismo se pueden tratar a través del conjunto de coeficientes de ponderación o seguridad. La dificultad de detección -como sucede en trasteros o garajes -, o la facilidad de ataque, o la proximidad de parques de bomberos, o la existencia de medios automáticos de extinción son más difíciles de implantar en el modelo.

Una tarea inmediata sería definir un modelo analítico, que sin renunciar a recoger todas las variables, fuera más sencillo que el general aquí expuesto, pero consiguiera eliminar parte de las incoherencias del actual planteamiento en cuanto al diferente tratamiento necesario con cada material.

Por otro lado, contando con la resistencia que ofrece la albañilería profusamente utilizada en nuestras latitudes, sería interesante poder determinar en qué categoría o tipología de edificios no es preciso analizar la agresión de incendio, permitiendo invertir ese esfuerzo en otros aspectos mucho menos formulados todavía y tan esenciales o más para suministrar seguridad a incendios, como serían la evacuación y la propagación de humos.

Mucho nos tememos que, igual que sucede con la acción de viento, la de fuego dependa fuertemente de la tipología constructiva, de forma que de antemano puede establecerse tajantemente que determinadas construcciones poseen la suficiente resistencia al fuego, al menos en el sentido que aquí hemos presentado. 